\title{
Removal of various pollutants from leachate using a low cost technique: integration of electrolysis with activated carbon contactor
}

\begin{abstract}
Landfill leachate contains a high concentration of organic pollutants that are active agents in water pollution. This study was conducted to remove various pollutants from landfill leachate through electrolysis and activated carbon (AC) treatments. A simple electrolytic reactor was designed to investigate the removal efficiency of these treatments for biochemical oxygen demand (BOD), chemical oxygen demand (COD), total suspended solids (TSSs), and total dissolved solids (TDSs) from landfill leachate at different electric current densities (CDs) and retention times (RTs). The results showed that the highest removal efficiencies for BOD and COD were 75.6 and $57 \%$, respectively, under a 7-V current for $4 \mathrm{~h}$. It was also found that BOD, COD, TSS, and TDS removal efficiencies improved in proportion to an increase in CD and RT. However, $\mathrm{pH}$ gradually increased with an increase in $\mathrm{CD}$ and RT. A number of treated leachate samples were further polished by AC filtration to compare the effect of this additional process on the removal of color, BOD, COD, TSS, and TDS. This secondary treatment resulted in a higher removal of color and other pollutants than electrolysis alone. At $4 \mathrm{~h} \mathrm{RT}$, the BOD removal efficiency was $54.6 \%$ at $3 \mathrm{~V}$ and $66.4 \%$ at $5 \mathrm{~V}$, and the efficiency increased to 61.5 and $70.5 \%$, respectively, after treatment by AC filtration. Under the same conditions, COD removal efficiency increased from 7.5 to $38.5 \%$ at $3 \mathrm{~V}$ and from 31.1 to $49.5 \%$ at $5 \mathrm{~V}$. TSS and TDS removal efficiencies were also significantly improved by AC filtration. It is therefore concluded that $7 \mathrm{~V}$ of $\mathrm{CD}$ and $4 \mathrm{~h}$ of RT are the optimum parameters for removing pollutants from leachate and that the secondary treatment of AC filtration is an efficient method of further polishing.
\end{abstract}

Keyword: Leachate; Electrolysis; Activated carbon; Pollutants; BOD 